\title{
SELECCIÓN DE POEMAS
}

Andrea Alzati*

\section{TODOS MIS QUCHILLOS (FRAGMENTOS)}

brillantes cuchillos

atraviesan manzanas rojas

manzanas rojas

son atravesadas por cuchillos de distintos tamaños y formas

una manzana atravesada por un cuchillo

es un animal nuevo

aun después de haber sido capturado sigue huyendo

manzana roja en su papel de fruta dulce en las esquinas

presume su cuchillo

se mece orgullosa

curvas casi círculo

el cuchillo que me atraviesa

corta siempre y cuando

me esté quieta

una vez partida en dos

comenzará la huida

en la mesa está la manzana

y el cuchillo está en otra parte

*Andrea Alzati (Guanajuato, 1989) es poeta y artista visual, autora de Animal doméstico (Malasuerte, 2017), Algo tan oscuro que no tiene nombre (Dharma Books, 2018) y Todos mis quchillos (Komorebi, 2019). Fue becaria del FONCA en el área de poesía. 
el cuchillo está bajo la mesa

aparece como aparece el sol

tras los edificios todos ventanas

o como aparece

o desaparece un muro

de la noche a la mañana

nadie espera el cuchillo

excepto cuando llega

todos exclaman

¡claro, ahí estabas!

$[\ldots]$

el cielo es atravesado por un pájaro

el pájaro atravesado por una bala de plomo

la mesa es atravesada por los platos

los tenedores

los manteles bordados

el frutero y las frutas

el jarrón con flores

el candelabro y la vela encendida

las mujeres de tres generaciones que sirven comida día tras día atraviesan la mesa

los ojos de las mujeres de tres generaciones

vistos bajo el microscopio

contienen cuchillos que giran

cuchillos de distintos tamaños y formas

flotan dentro de sus ojos 


\section{$[\ldots]$}

una mandarina se cuela en la escena

cuchillos de distintos tamaños y formas

flotan sobre el mar

el corazón del mar es una perla

el mar no tiene corazón

el corazón de los cuchillos de distintos tamaños y formas

son perlas

[...]

el mar es atravesado por tu nombre

tu nombre es dulce tiene esquinas

rompe los cuchillos

cierra el cielo

se alimenta de mandarina

no tiene corazón 